\title{
Local 5,7-Dihydroxytryptamine Lesions of Rat Amygdala: Release of Punished Drinking, Unaffected Plus-Maze Behavior and Ethanol Consumption
}

Wolfgang Sommer, M.D., Ph.D., Christian Möller, M.D., Ph.D., Lisa Wiklund, B.Sc., Annika Thorsell, Ph.D., Roberto Rimondini, Ph.D., Hans Nissbrandt, M.D., Ph.D., and Markus Heilig, M.D., Ph.D.

Several serotonergic drugs are effective for anxiety disorders, but underlying mechanisms are unclear, and findings in experimental animals are difficult to reconcile with human data. It has been proposed that differential effects of serotonin within specific anatomical systems may account for these difficulties, and the amygdala has been suggested as one of the structures involved. To examine this hypothesis, the neurotoxin 5,7-dihydroxytryptamine was administered locally in rat amygdala. Within the amygdala, serotonin was depleted by approximately $80 \%$, with other transmitters unaffected, and serotonin transporter labelling was decreased by approximately $85 \%$. Cortical areas near the lesion site were also affected, although to a lesser degree. Other forebrain areas were unaffected. Lesions resulted in a specific anticonflict effect in a punished drinking test, but did not influence elevated plus-maze behavior (under baseline conditions and after restraint stress), locomotor activity or ethanol intake. These data suggest that the punished drinking test and the elevated plus-maze may activate different components of fear circuitry, and that the serotonergic input to the amygdala specifically participates in fear-related behavioral suppression mediated by this structure.

[Neuropsychopharmacology 24:430-440, 2001] (C) 2001 American College of Neuropsychopharmacology. Published by Elsevier Science Inc.
KEY WORDS: Serotonin; Amygdala; Anxiety; Conflict; Ethanol consumption; Locomotion

Accumulating data indicate that serotonin uptake inhibitors are clinically effective for most if not all anxiety disorders (Perse et al. 1987; Den Boer and Westenberg

From the Addiction Centre South, Dept of NEUROTEC, Karolinska Institute, Stockholm, Sweden (WS, CM, LW, AT, RR, MH), Dept of Pharmacology, Göteborg Univ, Göteborg, Sweden (HN).

Address correspondence to: Wolfgang Summer, M.D., Ph.D. Addiction Centre South, M46 Huddinge University Hospital, S-14186 Huddinge, Sweden, Tel.: 46-8-5858-666, E-mail: wolfgang.sommer@ neurotec.ki.se

Received November 19, 1999; revised August 18, 2000; accepted August 26, 2000.
1988; Katzelnick et al. 1995; Rocca et al. 1997; Ballenger et al. 1998). While this provides renewed evidence for an involvement of 5-HT transmission in mechanisms of fear and anxiety, the role of serotonergic transmission in this context is not well understood. Experimental findings in animal studies aimed at elucidating serotonergic mechanisms in fear and anxiety have been inconsistent, possibly due to the diversity of central 5-HT systems.

Thus, a 'classical hypothesis' states that increased 5-HT transmission is anxiogenic and reduction is anxiolytic. This is supported by data from animal models based on fear-induced response inhibition, such as conflict tests, for example. However, in animal models which rely on suppression of exploratory behavior by an innate fear stimulus, such as the elevated plus-maze, 
the effects are more variable. Furthermore, effects opposite to those expected according to the 'classical hypothesis' have been obtained in studies which have used active escape or avoidance of an aversive stimulus. Finally, the 'classical hypothesis' is seemingly difficult to reconcile with the clinical anti-anxiety actions of serotonin uptake inhibitors, as these compounds are thought to potentiate serotonergic transmission (Graeff et al. 1996; Handley and McBlane 1993a).

On the basis of these and similar contradictions, the role of 5-HT in anxiety has been questioned, and it has been proposed that this mediator may instead primarily be involved in response inhibition and impulse control (Soubrié 1986). To reconcile these views, Deakin and Graeff (1991) have proposed a dual role of 5-HT action in anxiety. According to this hypothesis, ascending fibers from the dorsal raphe nucleus might facilitate integrated fear responses to distal stimuli through actions on the amygdala, while an inhibition of fight/flight responses to proximal stimuli could simultaneously be exerted by projections to the periaqueductal gray matter. The functional anatomy of central 5-HT systems in relation to this hypothesis has, to our knowledge, not been systematically studied.

An experimental strategy which can be followed to examine the functional role of 5-HT transmission is to lesion neurochemically serotonergic innervation. The neurotoxin 5,7-dihydroxytryptamine (5,7-DHT) has been widely used for global lesions of the 5-HT system or lesions of distinct groups of serotonergic neurons (Daly et al. 1974; Baumgarten et al. 1982). This approach leads to widespread reductions in 5-HT levels (Fischette et al. 1987). Animals with such general serotonergic lesions display decreased measures of experimental anxiety in paradigms of social and aggressive behavior (File et al. 1979), in the elevated plus-maze test (Briley et al. 1990), in conflict tests (Soderpalm and Engel 1991; Tye et al. 1977), and increase voluntary ethanol intake (Richardson and Novakovski 1978; Melchior and Myers 1976; Myers and Melchior 1975; Ho et al. 1974).

However, the 5,7-DHT studies listed above have not addressed the anatomical location(s) mediating 5,7-DHT effects on experimental anxiety. In this context, the amygdala complex provides an obvious candidate structure. Extensive animal data link the amygdala to mechanisms of fear and anxiety, and suggest this function to be conserved through phylogenesis (Pitkanen et al. 1997; Davis et al. 1994; Heilig et al. 1994). More recently, studies of patients with localized brain lesions, and functional brain imaging experiments have provided evidence that the role of the amygdala complex has remained similar in humans (Adolphs et al. 1994; Adolphs et al. 1995; Morris et al. 1998; Whalen et al. 1998). Also, it has been reported that the amygdala receives an important serotonergic input from the dorsal raphe nucleus (Ma et al. 1991).
Here, we therefore asked whether the serotonergic input to the amygdala may be involved in mechanisms of experimental anxiety. Localized 5,7-DHT lesions were produced stereotactically within the amygdala. The extent of the lesions was characterized using biochemical measures and autoradiographic labeling of serotonergic terminals. Levels of experimental anxiety were studied in a punished drinking paradigm, and in the elevated plus-maze, two pharmacologically validated and well established animal models of anxiety. Voluntary ethanol consumption was analyzed in a twobottle, free choice procedure.

\section{MATERIALS AND METHODS}

\section{General Design}

The following groups, subjected to surgery on separate occasions, were used: Group 1 was 5 lesioned vs. 5 sham-operated controls; all these subjects were used for biochemistry. Group 2 was 16 lesioned vs. 16 shamoperated subjects. From this group, data were obtained for weights and locomotor activity $(n=16)$, followed the next day by plus-maze testing under baseline conditions ( $\mathrm{n}=12-15$, due to some subjects not completing the procedure); after an additional week, plus-maze testing preceded by restraint $(n=10$, randomly selected from each total group of 16); and after an additional week the ethanol consumption procedure $(\mathrm{n}=$ 12 , randomly selected from each total group of 16). Group three was 8 vs. 8 subjects, used for the Vogel procedure $(\mathrm{n}=8)$, and following one week recovery, for 5-HT transporter binding ( $\mathrm{n}=5$, randomly selected from each total group of 8 ).

\section{Subjects}

Male Sprague-Dawley rats (Bee Kay, Sollentuna, Sweden), weighing $220-250 \mathrm{~g}$ at the start of the experiments were housed in groups of four per cage under controlled light-dark conditions (light on at $7 \mathrm{AM}$ and off at $7 \mathrm{PM})$, at a controlled temperature $\left(21-23^{\circ} \mathrm{C}\right)$. Animals were allowed free access to food and water at all times except during the punished drinking procedure. Animals were allowed to adapt to the animal facility for at least seven days prior to any procedures. Following surgery, a minimum of one week was allowed. The day before the first behavioral experiment subjects were handled once for five minutes. All experiments were approved by Stockholm South Animal Ethics Committee (permit S85-89/98).

\section{Lesion Procedure}

Animals were anesthetized with ketamine $(60 \mathrm{mg} / \mathrm{kg}) /$ xylazine $(10 \mathrm{mg} / \mathrm{kg})$ and placed in a stereotactic appara- 
tus. To block noradrenaline uptake sites all animals received desipramine $(20 \mathrm{mg} / \mathrm{kg}$, i.p., Sigma) 30 minutes before anesthesia. Bilateral lesions of serotonergic terminals in the amygdala were made by microinjecting $5,7-\mathrm{DHT}(4 \mu \mathrm{g} / \mu \mathrm{l}$ in $0.9 \% \mathrm{NaCl}, 0.1 \%$ ascorbic acid $)$ at a rate of $0.5 \mu \mathrm{l} / \mathrm{min}$. A dose of $4 \mu \mathrm{g}$ was used for each injection, as preliminary experiments indicated loss of biochemical selectivity with a higher dose of 5,7-DHT (16 $\mu \mathrm{g})$. The toxin was administered via 22-gauge needles attached to $10 \mu \mathrm{l}$ glass Hamilton syringes, fitted into a Kopf microinjection pump. Coordinates were $2.3 \mathrm{~mm}$ posterior and $\pm 4.4 \mathrm{~mm}$ lateral to bregma, and $8.5 \mathrm{~mm}$ ventral to the skull surface, with the tooth bar at $3.3 \mathrm{~mm}$ below interaural line (Paxinos and Watson 1986). After injection, the needle was left in place for additional three minutes. Control animals received vehicle injections into the same coordinates. Both lesioned and sham operated subjects recovered successfully from surgery. The lesions did not affect postoperative weight gain (Table 1).

\section{Biochemistry}

Animals for analysis of neurotransmitter tissue concentration were sacrificed by decapitation. Brains were taken out and dissected on ice. Samples of cortex, amygdala, hypothalamus and raphe were prepared for determining tissue concentration of noradrenaline (NA), dopamine (DA) serotonin (5-HT) and 5-hydroxyindoleacetic acid (5-HIAA). Cortex, amygdala, and hypothalamus samples were prepared from a 2-mm thick coronal slice, taken in a Kopf brain slicer by placing the rostral blade on the caudal edge of the chiasma opticum. For preparation of the raphe nucleus the rostral blade was placed $6 \mathrm{~mm}$ behind this landmark, and a second 2-mm coronal slice was obtained. From the rostral slice, cortical and hypothalamic tissues were dissected out, while amygdala tissue was obtained using a punch ( $2 \mathrm{~mm}$ diameter). From the caudal slice, the raphe area was obtained using a punch $(3 \mathrm{~mm}$ diameter). Samples were weighed, rapidly frozen, and stored at $-70^{\circ} \mathrm{C}$ until assayed.

Samples were homogenized with an ultrasonic disrupter in $0.1 \mathrm{M} \mathrm{HClO}_{4}$ containing $4.5 \mathrm{mM} \mathrm{Na}_{2}$ EDTA and $1.6 \mathrm{mM}$ reduced glutathione. Biochemical analysis was performed by means of high performance reversephase ion-pair liquid chromatography (HPLC) with

Table 1. Post-operative Body Weight Development in 5,7DHT Amygdala Lesioned and Control Rats ( $n=16 /$ Group; Mean $g \pm$ S.E.M.)

\begin{tabular}{lcc}
\hline & Day $\mathbf{1}$ & Day 15 \\
\hline Control & $237.8 \pm 2.29$ & $326.2 \pm 4.82$ \\
$5,7-$ DHT & $234.4 \pm 2.33$ & $327.3 \pm 3.05$ \\
\hline
\end{tabular}

electrochemical detection essentially according to standard procedure (Elverfors and Nissbrandt 1991). One chromatography system was used for detecting NA-, DA-, 5-HT and 5-HIAA-concentrations after direct injection of supernatant of tissue homogenate (Magnusson et al. 1980). The electrochemical detector was set at $+0.81 \mathrm{~V}$. The mobile phase consisted of $0.015 \mathrm{M}$ $\mathrm{K}_{2} \mathrm{HPO}_{4}, 0.035 \mathrm{M}$ citric acid, $0.054 \mathrm{mM} \mathrm{Na}_{2}$-EDTA, 0.43$0.52 \mathrm{mM}$ Na-octyl-sulphate and $9-11 \%$ methanol $(\mathrm{pH}$ $2.75-2.85)$. The flow rate was $1.5-2 \mathrm{ml} / \mathrm{min}$.

For amygdala and cortex, where biochemical measures were separately obtained for the left and the right side, the mean of these two values was calculated for each subject, and these means were used in the statistical analysis. For hypothalamus and raphe, a single reading was obtained for each subject, and that reading was used directly. Within each region, lesioned and control subjects were compared using one-way ANOVAs. To correct for multiplicity of comparisons, resulting $p$-values were corrected using Holm's improved weighted Bonferroni procedure (Holm 1979). The corrected $p$-values are shown.

\section{$\left[{ }^{3} \mathrm{H}\right]$ citalopram Binding}

Animals for the binding analysis were sacrificed by decapitation. Brains were removed, cut into blocks using a Kopf Brain Slicer, and frozen rapidly at $-40^{\circ} \mathrm{C}$, using isopentane. Tissues were mounted on a cryostat, and 14 $\mu \mathrm{m}$ coronal sections were obtained, mounted on microscopic glass slides and stored at $-70^{\circ} \mathrm{C} .\left[{ }^{3} \mathrm{H}\right]$ citalopram binding was performed as described ( $\mathrm{D}^{\prime}$ Amato et al. 1987). Briefly, the slides were warmed up to room temperature and preincubated in $50 \mathrm{mM}$ Tris- $\mathrm{HCl}$ buffer (pH 7.4) containing $120 \mathrm{mM} \mathrm{NaCl}$ and $5 \mathrm{mM} \mathrm{KCl}$ for 15 minutes at room temperature. The slides were then incubated in an assay buffer containing $1 \mathrm{nM}\left[{ }^{3} \mathrm{H}\right]$ citalopram in $50 \mathrm{mM}$ Tris- $\mathrm{HCl}$ buffer ( $\mathrm{pH}$ 7.4) containing 120 $\mathrm{mM} \mathrm{NaCl}$ and $5 \mathrm{mM} \mathrm{KCl}$ for 60 minutes at room temperature. Nonspecific binding was estimated by inclusion of $1 \mu \mathrm{M}$ unlabelled paroxetine in the incubation buffer. After the incubation, slides were dipped (1-2 sec) and then washed $2 \times 10$ minutes in ice cold preincubation buffer, rinsed in distilled water and dried under a stream of cold air. Sections were exposed together with ${ }^{3} \mathrm{H}$-standards (microscales) on ${ }^{3} \mathrm{H}$-screen for a BAS 5000 phosphorimager (Fuji) for five days. Analysis of photostimulated luminescence (PSL) was done with the Image Gauge software (Fuji). Within each region, lesioned and control subjects were compared using oneway ANOVAs. Resulting $p$-values were corrected for multiplicity of comparisons using Holm's improved weighted Bonferroni procedure (Holm 1979). The corrected $p$-values are shown. Binding data between basolateral and central amygdala within the sham group were compared using a paired $\mathrm{t}$-test. 


\section{Punished Drinking Test}

A modified Vogel's drinking test (Vogel et al. 1971) was used as recently described (Möller et al. 1997). Training and testing of animals was performed in sound-attenuated operant chambers (Med Associates, St Albans, VT) equipped with a grid floor of stainless steel bars and a drinking bottle containing $5 \%(\mathrm{w} / \mathrm{v})$ glucose solution. Following $24 \mathrm{~h}$ of water deprivation, starting postoperative day 10, animals were habituated for $12 \mathrm{~min}$ to the chamber. During this time, free access was given to the glucose solution. After an additional $24 \mathrm{~h}$ period of water deprivation, animals were adapted once more to the same test chamber for a further $12 \mathrm{~min}$, again with free access to the glucose solution. Finally, after a further 24 $h$ period of water deprivation, animals were returned to the operant chamber for the testing session.

Behavioral testing was under the control of a computerized system (Med Associates, St Albans, VT). Contact with the drinking spout was detected electronically. A session consisted of the following components:

1. Subject was introduced into the chamber, and allowed to establish drinking behavior. On detection of contact between the animal and the drinking spout, a "drinking episode" was registered, with no other consequences for the subject. To conform with the punished drinking component, additional contacts during the two seconds following detection were not registered. Subjects were allowed three drinking episodes before the session timer started.

2. After the timer was started, a 4-min unpunished drinking component followed, during which drinking episodes, defined as above, continued to be registered without shock being administered. This component serves as an internal control for drinking motivation and performance.

3. Finally, an 8-min punished drinking ("conflict") component started. During this component, on detection of contact a drinking episode was registered, and a $0.20 \mathrm{~mA}$ electric current was switched on between the drinking spout and the grid floor, for a fixed interval of two seconds. Using this method, during each drinking episode, shock is delivered while the subject remains in contact with the drinking spout, or for a maximum of two seconds. Additional contacts during the 2-sec shock interval can not be detected by the contact lickometer due to the presence of the shock current.

Within unpunished and punished component, lesioned and control subjects were compared using oneway ANOVAs. Following the completion of the conflict procedure, shock thresholds were tested as described previously (Möller et al. 1999).

\section{Elevated Plus-Maze}

Plus-maze testing was essentially as originally described (Pellow et al. 1985; Pellow and File 1986). The apparatus was made of black plastic, and consisted of two open arms measuring $50 \times 10 \mathrm{~cm}$, and two arms of the same size surrounded by $40 \mathrm{~cm}$ high end and side walls. The arms were connected by a central area measuring $10 \times 10$ $\mathrm{cm}$, and the maze was $50 \mathrm{~cm}$ above the floor during testing, which was undertaken under dim red light. Behavior was scored by a trained observer unaware of treatment conditions. Subjects were placed in a novel environment (an empty operant chamber) for five minutes prior to testing; this has been shown to increase exploratory activity and improve the reliability of subsequent plus-maze testing (Pellow et al. 1985). At the beginning of a session, the rat was placed in the central area of the maze, facing one of the open arms. The number of entries made into open and closed arms and the time spent in open and closed arms were recorded over a 5-min session. An arm entry was defined as all four paws into an arm. The percentage of time spent in the open arms and of entries into the open arm, as well as the total number of entries were compared using one-way ANOVAs.

Animals were tested on the elevated plus-maze twice: Under baseline condition, and, one week later, one hour following the completion of a 1-hr restraint stress in a plexiglass tube (transparent plastic cylinder of $6 \mathrm{~cm}$ diameter and an adaptable length of maximal $20 \mathrm{~cm}$ ).

Table 2. Biochemical Measures in 5,7-DHT Lesioned and Control Rats. Values Represent Means \pm S.E.M. in ng/g Wet Tissue. ${ }^{* * *}$ Indicates Corrected $p<.001 ;{ }^{* *}$ Corrected $p<.01$; n.d. Not Determined. For Detailed Statistics, see Results Section

\begin{tabular}{llcccc}
\hline Region & Treatment & 5-HT & 5-HIAA & DA & NA \\
\hline amygdala & Sham & $171.9 \pm 25.0$ & $271.7 \pm 37.0$ & $525.6 \pm 97.5$ & $4200.0 \pm 349.8$ \\
& 5,7-DHT & $33.7 \pm 10.4^{* * *}$ & $88.2 \pm 15.0^{* *}$ & $486.4 \pm 99.3$ & $3851.9 \pm 245.4$ \\
cortex & Sham & $145.0 \pm 9.7$ & $363.0 \pm 13.9$ & $49.3 \pm 9.9$ & $122.8 \pm 7.3$ \\
& 5,7-DHT & $55.1 \pm 6.0^{* * *}$ & $130.1 \pm 10.1^{* * *}$ & $89.5 \pm 24.6$ & $133.6 \pm 6.8$ \\
hypothalamus & Sham & $175.8 \pm 19.7$ & $1136.5 \pm 143.0$ & $322.3 \pm 35.6$ & n.d. \\
& 5,7-DHT & $196.2 \pm 33.4$ & $956.4 \pm 101.0$ & $343.0 \pm 53.2$ & n.d. \\
raphe & Sham & $251.2 \pm 36.4$ & $1541.0 \pm 157.1$ & $74.8 \pm 21.8$ & n.d. \\
& 5,7-DHT & $346.4 \pm 67.9$ & $1759.4 \pm 214.0$ & $86.0 \pm 25.2$ & n.d. \\
\hline
\end{tabular}




\section{Locomotor Activity}

Exploratory locomotor activity was determined in sound attenuated chambers containing locomotor activity cages $(380 \times 200 \times 160 \mathrm{~mm})$ equipped with infra-red beam detection (Med Associates, St Albans, VT). Interbeam distance was $8.5 \mathrm{~cm}$ horizontally and $6.5 \mathrm{~cm}$ vertically, and activity was recorded for 30 minutes in intervals of $10 \mathrm{~min}$. Horizontal locomotor activity and rearings of lesioned and control animals were compared separately, using two-way ANOVA for treatment, time and treatment $\mathrm{X}$ time.

\section{Ethanol Preference Procedure}

A two bottle, free choice procedure was used (Spanagel et al. 1995). Animals were placed in single cages, and two bottles containing water or increasing concentrations of ethanol were made available continuously as a free choice of the animal. Ethanol concentration was increased every fifth day as follows: $2 \%$ on days $1-5,4 \%$ on days $6-10$, and $6 \%$ on days $11-15$ (v/v solutions). To mask taste aversion, $0.2 \%$ saccharin $(\mathrm{w} / \mathrm{v})$ was added to both the water and the ethanol solutions. Bottle positions were changed randomly every day to prevent position habit from developing. Consumption of ethanol and water, as well as body weights, were measured daily. Both ethanol and total liquid consumption in lesioned and control animals were compared by two-way ANOVA with respect to treatment and time. Weight gain was compared using one-way ANOVA.

\section{RESULTS}

\section{Biochemistry}

Results of the biochemical analysis ( $\mathrm{n}=5$ /group) are shown in Table 2. In amygdala, tissue levels of 5-HT was reduced by $80.5 \%(\mathrm{~F}[1,8]=34.8$, corrected $p=.0005)$ and 5 -HIAA by $67.5 \%(\mathrm{~F}[1,8]=22.2$, corrected $p=.003)$ compared to the control group. There was also a significant reduction in 5-HT and 5-HIAA levels in cortical tissue overlying the injection site (5-HT: $62.0 \%$ reduction; $\mathrm{F}[1,8]=$ 49.0 , corrected $p=.0001 ; 5$-HIAA: $64.2 \%$ reduction, $\mathrm{F}[1,8]=$ 420.2 , corrected $p<.0001$ ). No lesion effect was seen in the hypothalamus or in the raphe area, although a trend toward increased 5-HT and 5-HIAA levels was seen in the latter region. Tissue concentrations of NA and DA were not affected by the lesion in any analyzed region.

\section{$\left[{ }^{3} \mathrm{H}\right]$ citalopram Binding}

$\left[{ }^{3} \mathrm{H}\right]$ citalopram binding was analyzed in the amygdala, and in several regions around the lesion site and of the forebrain ( $\mathrm{n}=4-5$; Figure 1; Table 3).

Within the amygdala, a heterogeneous distribution of $\left[{ }^{3} \mathrm{H}\right]$ citalopram binding was found in sham-lesioned subjects. Binding in the basolateral/lateral amygdala was approximately three times higher compared to the central amygdala $(635.8 \pm 46.7$ vs. $224.5 \pm 35.6 ; \mathrm{t}=9.52$, $p=.0025$; BLA vs. CeA, respectively; Figure 2).

In lesioned subjects, binding sites were reduced by $83 \%$ in amygdala $(\mathrm{F}[1,8]=64.04$, corrected $p=.0001)$, and a significant reduction was also found in the nearby piriform cortex $(42 \%$ reduction; $F[1,8]=38.59$, corrected $p=.005$ ) and in the nearby parietal cortex
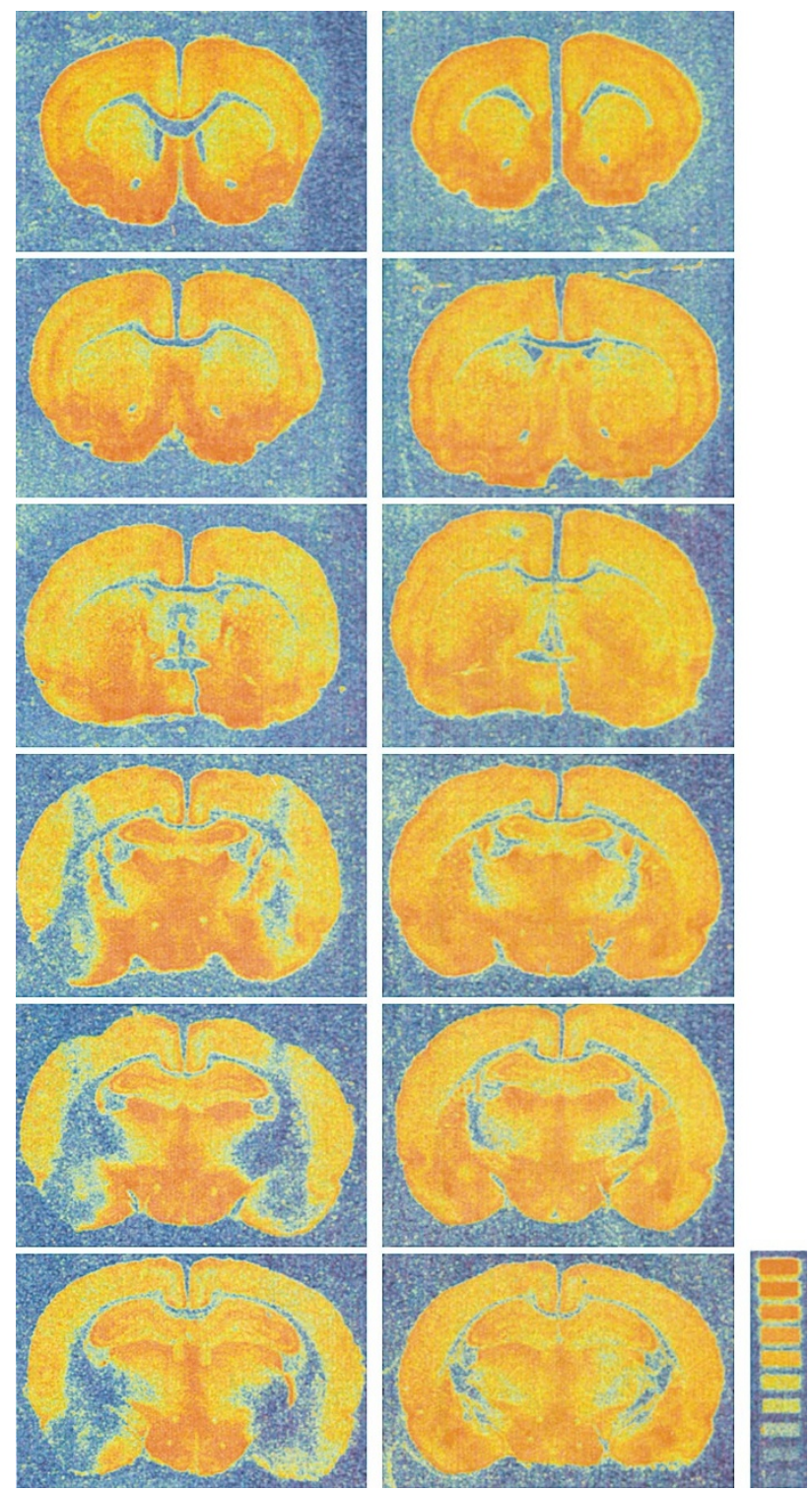

Figure 1. Autoradiograms showing the distribution of $\left[{ }^{3} \mathrm{H}\right]$ citalopram binding sites in representative coronal sections of 5,7-DHT lesioned (left panel) and control animals (right panel). Levels are, from top to bottom: 2.0, 1.0, -0.4, $-1.8,-2.3$, and $-3.3 \mathrm{~mm}$ relative bregma. The standard shows color distribution from $322.2 \mathrm{PSL} / \mathrm{mm}^{2}$ (top) to 2.7 $\mathrm{PSL} / \mathrm{mm}^{2}$ (bottom). Quantitative results for regions of interest are given in Table 3. 
Table 3. Density of $\left[{ }^{3} \mathrm{H}\right]$ Citalopram Binding Sites in 5,7-DHT Lesioned and Control Rats. Values Represent Means \pm S.E.M. $\left(\mathrm{nCi} / \mathrm{mg} / \mathrm{mm}^{2}\right) ;{ }^{*}$ Indicates Corrected $p<.05,{ }^{* *} p<.01$ and *** Indicates Corrected $p<.001$. For Detailed Statistics, See Results Section. Values in Parentheses Refer to Bregma Levels in mm According to Paxinos and Watson (1986)

\begin{tabular}{lcc}
\hline Region & Sham & 5,7-DHT \\
\hline Pre/infralimbic cortec (2.0) & $461.5 \pm 24.74$ & $436.4 \pm 28.57$ \\
Cingulate cortex (1.0) & $278.4 \pm 18.67$ & $252.3 \pm 17.29$ \\
Parietal cortex (1.0) & $312.1 \pm 27.69$ & $286.2 \pm 48.83$ \\
Accumbens core (1.0) & $322.6 \pm 48.60$ & $353.7 \pm 20.65$ \\
Accumbens shell (1.0) & $586.2 \pm 74.68$ & $639.3 \pm 112.08$ \\
Dorsal striatum (1.0) & $216.5 \pm 17.96$ & $175.0 \pm 38.38$ \\
Ventrolateral striatum (1.0) & $342.1 \pm 47.80$ & $319.9 \pm 69.39$ \\
Cingulate cortex (-0.4) & $259.5 \pm 30.12$ & $306.9 \pm 25.19$ \\
Bed nucleus stria terminalis $(-0.4)$ & $349.1 \pm 47.56$ & $474.6 \pm 48.27$ \\
Globus pallidus (-0.4) & $337.3 \pm 12.67$ & $366.8 \pm 60.22$ \\
Dorsal hippocampus (-2.5) & $346.3 \pm 28.98$ & $365.5 \pm 25.40$ \\
Parietal cortex (-2.5) & $238.6 \pm 24.60$ & $148.4 \pm 14.46^{*}$ \\
Piriform cortex (-2.5) & $270.5 \pm 14.05$ & $157.2 \pm 25.16^{* *}$ \\
Amygdala complex (-2.5) & $477.4 \pm 31.53$ & $79.1 \pm 14.33^{* * *}$ \\
Lateral Hypothalamus (-2.5) & $568.6 \pm 98.90$ & $562.6 \pm 70.30$ \\
\hline
\end{tabular}

$(38 \% ; \mathrm{F}[1,8]=10.55$, corrected $p=.01) .\left[{ }^{3} \mathrm{H}\right]$ citalopram binding was unaffected in the lateral hypothalamus and in forebrain regions rostral to the lesion.

\section{Vogel Punished Drinking Test}

Unpunished drinking did not differ significantly between sham operated and lesioned animals $(n=8 /$ group; $F[1,14]=0.23, p=.88$; Figure 3 ) Punished drinking was significantly elevated in lesioned subjects $(\mathrm{F}[1,14]=6.76, p=.02)$. Shock thresholds did not differ between groups (data not shown).

\section{Elevated Plus-Maze}

The 5,7-DHT lesion did not influence any behavioral parameter on the plus maze neither under baseline con- ditions ( $\mathrm{n}=12$ and $\mathrm{n}=15$ for sham and lesioned group, respectively; percent open arm time: $F[1,25]=$ $0.001, p=.96$; percent open arms entries: $\mathrm{F}[1,25])=0.47$, $p=.49$; total number of entries: $\mathrm{F}[1,25]=0.22, p=.64$ ) nor after acute stress $(n=10$ /group; percent open arm time: $\mathrm{F}[1,17]=1.8, p=.2$; percent open arms entries: $\mathrm{F}[1,17])=0.6, p=.45$; total number of entries: $\mathrm{F}[1,17]=$ $0.44, p=.51$; Table 4$)$.

\section{Locomotor Activity}

Locomotor activity of sham operated controls displayed an expected decay over $30 \mathrm{~min}$ of testing, indicating habituation to a novel environment. 5,7-DHT lesions affected neither total activity, nor decay over time, for neither horizontal locomotor activity: lesion effect $[\mathrm{F}(1,30)=0.77 ; \mathrm{NS}]$, time effect $[\mathrm{F}(2,60)=43.45 ; p<$

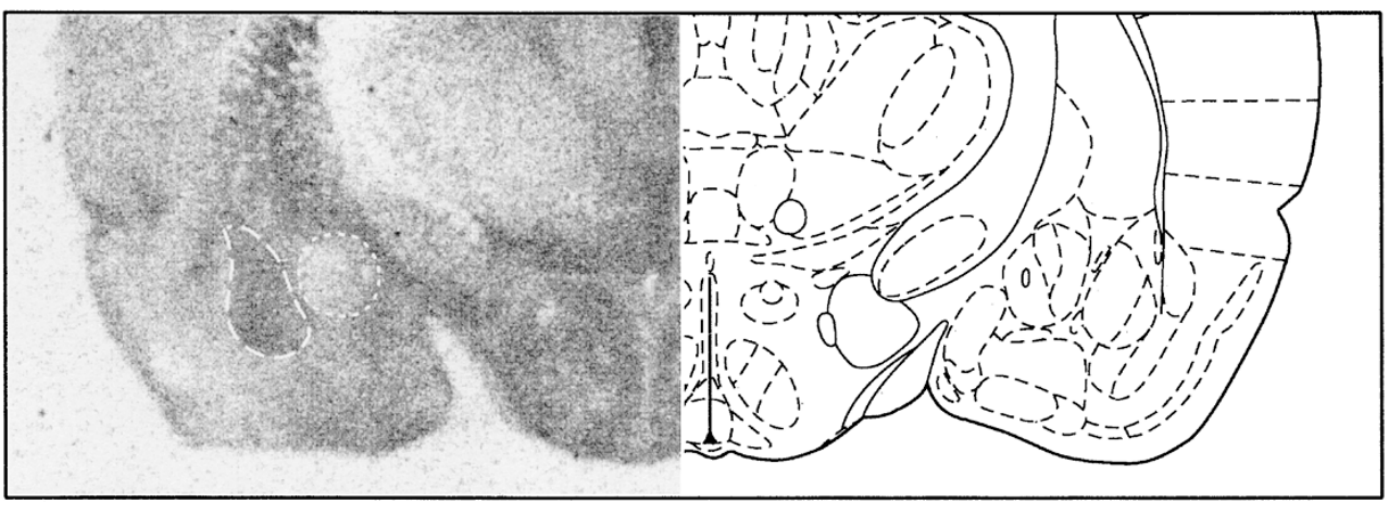

Figure 2. Autoradiogram demonstrating the heterogeneous distribution of $\left[{ }^{3} \mathrm{H}\right]$ citalopram binding intensity in the amygdala region of control animals. The border of the central amygdala (CeA) and the basolateral/lateral amygdala (BLA) are outlined on the autoradiogram (hatched line). The drawing is taken from the atlas of Paxinos and Watson at Bregma level $-2.5 \mathrm{~mm}$. Detailed statistics are given in the results section. 


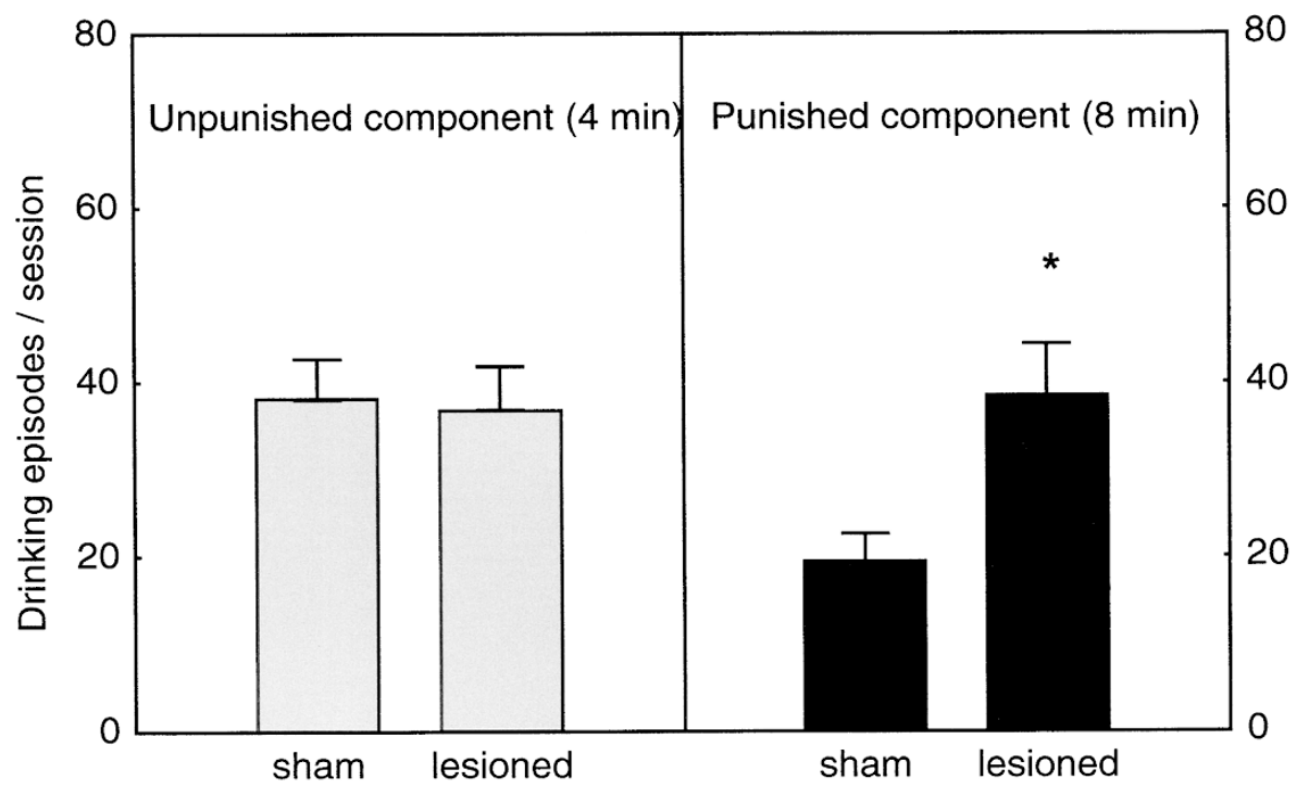

Figure 3. Conflict behavior of 5,7-DHT lesioned rats and controls. There was no difference in unpunished drinking between the two groups. In the punished drinking component, there was a significant increase in drinking of the lesioned rats $(p<.05)$. Number of drinking episodes is shown (mean \pm S.E.M.) during a 4-minute unpunished and an 8-minute conflict component.

.0001] and interaction $[\mathrm{F}(2,60)=0.39 ; \mathrm{NS}]$, nor rearings $[\mathrm{F}(1,30)=0.01 ; \mathrm{NS}]$, time effect $[\mathrm{F}(2,60)=52.46 ; p<$ $.0001]$ and interaction $[\mathrm{F}(2,60)=0.50 ; \mathrm{NS}]$. Total counts for horizontal locomotor activity and rearings were: $1857.6 \pm 133.82$ vs. $1667.6 \pm 169.75$ and $400.6 \pm 34.64$ vs. $427.6 \pm 29.93$; sham operated vs. lesioned subjects ( $n=16 /$ group), respectively.

\section{Ethanol Preference Procedure}

The weight of the animals ( $n=12$ /group) was followed daily and both ethanol and total liquid consumption were expressed per unit body weight. Ethanol and total liquid intake were analyzed separately, using two way ANOVA with respect to treatment and time (Table 5). No group difference was found for either parameter (ethanol intake: lesion effect $[\mathrm{F}(1,22)=0.03 ; \mathrm{NS}]$, time effect $[\mathrm{F}(14,308)=6.82 ; p<.0001]$ and interaction $[\mathrm{F}(14,308)=0.79 ; \mathrm{NS}]$; total liquid intake: lesion effect $[\mathrm{F}(1,22)=1.25 ; \mathrm{NS}]$, time effect $[\mathrm{F}(14,308)=32.01 ; p<$ $.0001]$ and interaction $[\mathrm{F}(14,308)=1.51$; NS $]$,). No difference in weight gain was observed over the 15 days of the procedure $(135.3 \pm 4.3$ vs. $141.0 \pm 2.2$; sham operated vs. lesioned subjects, respectively).

\section{DISCUSSION}

In order to study the functional role of the serotonergic input to the amygdala, we examined the feasibility of selectively lesioning serotonergic terminals in this structure using localized administration of 5,7-DHT. Biochemical data and radioligand labelling of serotonergic terminals indicate that a reasonable good degree of both biochemical and anatomical selectivity was in fact obtained.

Thus, a biochemical specificity was indicated by the finding that 5-HT and 5-HIAA were dramatically depleted within the amygdala, while the levels of NA and DA were left unaffected. The remaining amount of 5-HT and 5-HIAA within the amygdala may reflect a partially spared serotonergic input, but could alternatively be caused by an influx of transmitter from surrounding tis-

Table 4. Plus-maze Performance of Sham Operated and 5,7-DHT Lesioned Subjects. No Difference in Open Arm Exploration (\% Open/(Open+Closed); Mean \pm S.E.M.) under Baseline Conditions And after Restraint. For Detailed Statistics, see Results Section

\begin{tabular}{lll}
\hline & Control & 5,7-DHT \\
\hline Baseline & & \\
\hline \% time in open arms & $37.8 \pm 5.2$ & $37.7 \pm 4.1$ \\
\% entries in open arms & $39.1 \pm 3.0$ & $42.0 \pm 2.9$ \\
Total No entries & $17.4 \pm 1.3$ & $16.7 \pm 0.7$ \\
\hline Restraint stress & & \\
\hline \% time in open arms & $45.4 \pm 2.7$ & $53.2 \pm 4.8$ \\
\% entries in open arms & $44.0 \pm 3.1$ & $48.3 \pm 4.3$ \\
Total No entries & $17.9 \pm 1.2$ & $19.1 \pm 1.2$ \\
\hline
\end{tabular}


Table 5. Voluntary Ethanol (Upper) and Total Liquid (Lower) Consumption in 5,7-DHT Lesioned And Control Rats. Values Represent Means \pm S.E.M. in $\mathrm{g} / \mathrm{kg}$ for Ethanol Consumption And $\mathrm{ml} / \mathrm{kg}$ for Total Liquid Intake. There Are No Differences in Neither Ethanol Nor Water Consumption Between The Groups

\begin{tabular}{|c|c|c|c|c|c|}
\hline Treatment & \multicolumn{5}{|c|}{ Day } \\
\hline & 1 & 2 & 3 & 4 & 5 \\
\hline \multicolumn{6}{|l|}{$2 \% \mathrm{EtOH}$} \\
\hline Control & $3,10 \pm 0,44$ & $1,86 \pm 0,22$ & $1,54 \pm 0,27$ & $1,25 \pm 0,32$ & $1,24 \pm 0,32$ \\
\hline 5,7-DHT & $2,80 \pm 0,25$ & $1,89 \pm 0,28$ & $1,78 \pm 0,24$ & $1,17 \pm 0,15$ & $1,16 \pm 0,15$ \\
\hline $4 \% \mathrm{EtOH}$ & 6 & 7 & 8 & 9 & 10 \\
\hline Control & $2,83 \pm 0,53$ & $2,80 \pm 0,57$ & $2,66 \pm 0.47$ & $2,38 \pm 0,60$ & $1,92 \pm 0,41$ \\
\hline 5,7-DHT & $3,11 \pm 0,30$ & $2,63 \pm 0,34$ & $3,06 \pm 0,34$ & $2,25 \pm 0,42$ & $3,00 \pm 0,30$ \\
\hline $6 \% \mathrm{EtOH}$ & 11 & 12 & 13 & 14 & 15 \\
\hline Control & $2,32 \pm 0,65$ & $2,34 \pm 0,63$ & $2,33 \pm 0,72$ & $2,04 \pm 0,64$ & $2,59 \pm 0,86$ \\
\hline 5,7-DHT & $2,63 \pm 0,45$ & $2,63 \pm 0,45$ & $2,26 \pm 0,44$ & $2,17 \pm 0,51$ & $1,98 \pm 0,48$ \\
\hline \multirow[t]{2}{*}{ Treatment } & \multicolumn{5}{|c|}{ Day } \\
\hline & 1 & 2 & 3 & 4 & 5 \\
\hline Control & $271,82 \pm 28,21$ & $199,60 \pm 22,39$ & $160,26 \pm 11,02$ & $147,00 \pm 11,78$ & $145,94 \pm 12,24$ \\
\hline \multirow[t]{2}{*}{ 5,7-DHT } & $215,10 \pm 15,22$ & $166,44 \pm 15,32$ & $147,58 \pm 13,58$ & $138,06 \pm 10,86$ & $138,58 \pm 10,71$ \\
\hline & 6 & 7 & 8 & 9 & 10 \\
\hline Control & $134,69 \pm 10,47$ & $143,48 \pm 9,70$ & $137,47 \pm 9,81$ & $154,54 \pm 15,65$ & $131,68 \pm 11,45$ \\
\hline \multirow[t]{2}{*}{ 5,7-DHT } & $128,42 \pm 9,64$ & $135,59 \pm 11,27$ & $128,45 \pm 10,39$ & $133,21 \pm 11,63$ & $127,63 \pm 12,01$ \\
\hline & 11 & 12 & 13 & 14 & 15 \\
\hline Control & $129,50 \pm 8,64$ & $128,53 \pm 8,40$ & $136,15 \pm 14,16$ & $140,12 \pm 9,82$ & $133,64 \pm 15,97$ \\
\hline 5,7-DHT & $118,71 \pm 10,15$ & $118,77 \pm 10,30$ & $119,23 \pm 10,15$ & $116,90 \pm 9,74$ & $112,90 \pm 6,98$ \\
\hline
\end{tabular}

sue. It is noteworthy that biochemical specificity appears to be lost with higher amygdala doses of 5,7-DHT. In preliminary experiments, a dose of $16 \mu \mathrm{g} /$ amygdala, in addition to depleting 5-HT and 5-HIAA significantly suppressed both DA and NA levels (data not shown). In view of these findings, it seems likely that the functional effects observed following lesions obtained with the $4-\mu \mathrm{g} /$ amygdala dose were indeed related to the serotonergic denervation, rather than non specific tissue damage.

A trend increase in 5-HT levels was found in the raphe area following amygdala 5,7-DHT lesions. A possible explanation is that this reflects a compensatory response of the serotonergic cell bodies, through which changes in amygdala 5-HT levels might alter serotonergic transmission in other brain areas. Support for this type of mechanism has previously been obtained after unilateral 5,7-DHT injections into the lateral hypothalamus (Tsuiki et al. 1995).

Anatomical specificity of the lesion effect was analyzed by measuring the density 5 -HT transporter binding sites which are exclusively expressed by 5 -HT neurons. These data confirmed the biochemical findings within the amygdala, while the serotonergic input into a variety of other forebrain areas was unaffected. Serotonergic fibers passing through the lesion area thus do not appear to be influenced by the toxin. However, both a marked reduction of 5-HT and 5-HIAA levels and a destruction of 5-HT terminals was found in cortical areas surrounding the amygdaloid complex. With the present injection volume $(1 \mu \mathrm{l})$, some spread of the toxin thus seems to occur, and lead to a partial loss of anatomical specificity.

Functionally, serotonergic denervation of the amygdala led to a release of punished drinking in the conflict procedure. This effect appears to be behaviorally specific, since both locomotor activity, activity (total number of entries) on the elevated plus-maze, unpunished drinking and shock thresholds were unaffected. Our present results with local 5-HT depletion in the amygdala are in agreement with previously reported anti-conflict effects of generally reduced 5-HT neurotransmission (Soderpalm and Engel 1991; File et al. 1979; Briley et al. 1990; Thiebot et al. 1984; Tye et al. 1977). The finding that a similar effect is obtained following localized serotonergic denervation of the amygdala suggests that this structure might be an anatomical substrate for the anti-conflict effects obtained in the previous studies.

The finding of the present study is also in line with previous reports describing the effects of 5-HT agonists and antagonists after microinjection into the amygdala. Injection of 5-HT and the direct 5-HT agonist quipazine into the amygdala inhibits predatory and affective aggression (Pucilowski et al. 1985). Intra-amygdala injection of 5-HT and 8-OH-DPAT, a 5-HT1A agonist reduced punished responding, whereas the 5-HT2 antagonist methysergide released conflict behavior (Hodges et al. 1987). In addition, social interaction was increased after intraamygdala injection of several 5-HT3 antagonists, although these compounds were ineffective in a conflict test (Higgins et al. 1991). 
However, in the present study, selective serotonergic denervation of the amygdala differentially affected animal responding in two behavioral procedures commonly used to screen for anti-anxiety compounds: Suppression of punished drinking was diminished, but open arm exploration on the elevated plus-maze was unaffected. The dissociation between the two anxiety models is of interest in the context of three conceptual frameworks:

1. On the basis of similar dissociations, the possibility has been raised that the elevated plus-maze may refer to particular aspects of experimental anxiety, i.e. responses to continuous, complex environmental stimuli signaling unknown threat, as opposed to transitory, easily identifiable and controllable events, such as the shocks involved in conventional conflict procedures (Handley and McBlane 1993b). Thus, the present data might indicate that, within the amygdala, serotonin is involved in the processing of the latter, but not the former, type of stimuli.

2. In addition, differential results obtained in conflict tests and the plus-maze may be due to the markedly different stress levels inherent in these paradigms. In the absence of a challenge, cell body-selective ibotenic acid lesions of central, but not basolateral, amygdala produce anti-conflict effects in the punished drinking procedure, while leaving plus-maze behavior unaffected. However, when plus-maze testing was preceded by a 1-hr restraint stress, an anxiolytic-like effect of central amygdala lesions became apparent in the plus-maze (Möller et al. 1997). In the present study, we therefore examined the role of 5,7-DHT amygdala lesions on plus-maze behavior under both unstressed and stressed conditions. In contrast to the ibotenic acid lesions, serotonergic denervation was ineffective under both conditions. Since the central nucleus is the structure within the amygdala mediating stress effects on plus-maze behavior, the present finding appears to be in agreement with our observation that the central nucleus receives only a minor proportion of the serotonergic input to the amygdala.

3. Perhaps most importantly, our observations may support the theory put forward by Soubrié (1986) that the conflict paradigm, in addition to being a model of anxiety, may also reflect impulse control. Further evidence for this concept comes from both clinical and experimental data (Eriksson and Humble 1990; Griebel 1995) which demonstrate anti-conflict effects of reduced serotonergic neurotransmission. The notion that conflict procedures may be sensitive both to anti-anxiety drugs and manipulations leading to impaired impulse control is supported by recent findings that high doses of testosterone lead to a release of punished drinking (Bing et al. 1998). Thus, behavioral response inhibition mediated by the amygdala may involve serotonergic transmission, and constitute a basic module of behavioral regulation, utilized in an overlapping but differential manner by different behavioral programs.

In the present study, ethanol preference was unaffected by serotonergic denervation of the amygdala. This finding is in contrast with extensive data suggesting that global 5-HT depletion in the brain increases ethanol drinking (reviewed in LeMarquand et al. 1994). Thus, modulatory effect of central serotonin on ethanol intake are likely to be mediated by brain structures other than the amygdala. Furthermore, basal levels of experimental anxiety, as approached by the elevated plus-maze, have been reported to predict alcohol preference (Spanagel et al. 1995), and decreased voluntary ethanol consumption was observed in central amygdala lesioned rats, a treatment which produces anxiolyticlike effects (Möller et al. 1997). Since both plus-maze behavior and ethanol preference were unchanged by our 5,7-DHT lesions, while direct lesions of the central nucleus have been shown to affect both these behaviors, we find here further support for a conclusion that central nucleus function is not a major regulatory target for the serotonergic input to the amygdala.

In contrast, our binding data suggest that the basolateral/lateral nuclei receive the strongest 5-HT innervation within the amygdala complex. It has previously been demonstrated that basolateral/lateral amygdala is predominantly involved in fear learning, while the central and medial parts form the output of the amygdala, with major projections to the hypothalamus and brain stem regions (Kopchia et al. 1992; LeDoux 1992; LeDoux et al. 1990). Therefore, in addition to controlling fearinduced suppression of behavior, the serotonergic input to the amygdala may also be involved in fear learning, an aspect which will warrant further study.

\section{ACKNOWLEDGMENTS}

This study was supported by the Swedish Medical Research Council (grant K98-21X-10872-05B to MH).

\section{REFERENCES}

Adolphs R, Tranel D, Damasio H, Damasio A (1994): Impaired recognition of emotion in facial expressions following bilateral damage to the human amygdala. Nature 372:669-672

Adolphs R, Tranel D, Damasio H, Damasio AR (1995): Fear and the human amygdala. Journal of Neuroscience 15:5879-5891

Ballenger JC, Wheadon DE, Steiner M, Bushnell W, Gergel IP (1998): Double-blind, fixed-dose, placebo-controlled study of paroxetine in the treatment of panic disorder. American Journal of Psychiatry 155:36-42 
Baumgarten HG, Klemm HP, Sievers J, Schlossberger HG (1982): Dihydroxytryptamines as tools to study the neurobiology of serotonin. Brain Research Bulletin 9:131150

Bing O, Heilig M, Kakoulidis P, Sundblad C, Wiklund L, Eriksson E (1998): High doses of testosterone increase anticonflict behaviour in rat. European Neuropsychopharmacology 8:321-323

Briley M, Chopin P, Moret C (1990): Effect of serotonergic lesion on "anxious" behaviour measured in the elevated plus-maze test in the rat. Psychopharmacology 101:187189

D'Amato RJ, Largent BL, Snowman AM, Snyder SH (1987): Selective labeling of serotonin uptake sites in rat brain by $[3 \mathrm{H}]$ citalopram contrasted to labeling of multiple sites by $[3 \mathrm{H}]$ imipramine. Journal of Pharmacology \& Experimental Therapeutics 242:364-371

Daly J, Fuxe K, Jonsson G (1974): 5,7-Dihydroxytryptamine as a tool for the morphological and functional analysis of central 5-hydroxytryptamine neurons. Research Communications in Chemical Pathology \& Pharmacology 7:175-187

Davis M, Rainnie D, Cassell M (1994): Neurotransmission in the rat amygdala related to fear and anxiety. Trends in Neurosciences. 17:208-214

Deakin JF, Graeff FG (1991): 5-HT and mechanisms of defense. Journal of Psychopharmacol 5:305-315

Den Boer JA, Westenberg HG (1988): Effect of a serotonin and noradrenaline uptake inhibitor in panic disorder; a double-blind comparative study with fluvoxamine and maprotiline. International Clinical Psychopharmacology 3:59-74

Elverfors A, Nissbrandt H (1991): Reserpine-insensitive dopamine release in the substantia nigra? Brain Research 557:5-12

Eriksson E, Humble M (1990): Serotonin in psychiatric pathophysiology. In Pohl R, Gershon S (eds), The biological basis of psychiatric treatment. Karger AG, Basel, pp 81-119

File SE, Hyde JR, MacLeod NK (1979): 5,7-dihydroxytryptamine lesions of dorsal and median raphe nuclei and performance in the social interaction test of anxiety and in a home-cage aggression test. Journal of Affective Disorders 1:115-122

Fischette CT, Nock B, Renner K (1987): Effects of 5,7-dihydroxytryptamine on serotonin 1 and serotonin 2 receptors throughout the rat central nervous system using quantitative autoradiography. Brain Research 421:263279

Graeff FG, Guimaraes FS, De Andrade G, Deakin JF (1996): Role of 5-HT in stress, anxiety, and depression. Pharmacology, Biochemistry \& Behavior 54:129-141

Griebel G (1995): 5-Hydroxytryptamine-interacting drugs in animal models of anxiety disorders: more than 30 years of research. Pharmacology \& Therapeutics 65:319-395

Handley SL, McBlane JW (1993a): 5HT drugs in animal models of anxiety. Psychopharmacology 112:13-20

Handley SL, McBlane JW (1993b): An assessment of the elevated X-maze for studying anxiety and anxiety-modulating drugs. Journal of Pharmacological \& Toxicological Methods 29:129-138
Heilig M, Koob GF, Ekman R, Britton KT (1994): Corticotropin-releasing factor and neuropeptide $\mathrm{Y}$ : role in emotional integration. Trends in Neurosciences 17:80-85

Higgins GA, Jones BJ, Oakley NR, Tyers MB (1991): Evidence that the amygdala is involved in the disinhibitory effects of 5-HT3 receptor antagonists. Psychopharmacology 104:545-551

Ho AK, Tsai CS, Chen RC, Begleiter H, Kissin B (1974): Experimental studies on alcoholism. I. Increased in alcohol preference by 5.6-dihydroxytryptamine and brain acetylcholine. Psychopharmacologia 40:101-107

Hodges H, Green S, Glenn B (1987): Evidence that the amygdala is involved in benzodiazepine and serotonergic effects on punished responding but not on discrimination. Psychopharmacology 92:491-504

Holm S (1979): A Simple Sequentially Rejective Multiple Test Procedure. Scandinavian Journal of Statistics 6: 65-70

Katzelnick DJ, Kobak KA, Greist JH, Jefferson JW, Mantle JM, Serlin RC (1995): Sertraline for social phobia: a double-blind, placebo-controlled crossover study. American Journal of Psychiatry 152:1368-1371

Kopchia KL, Altman HJ, Commissaris RL (1992): Effects of lesions of the central nucleus of the amygdala on anxiety-like behaviors in the rat. Pharmacology, Biochememistry \& Behavior 43:453-461

LeDoux JE (1992): Brain mechanisms of emotion and emotional learning. Current Opinion Neurobiology 2:191197

LeDoux JE, Cicchetti P, Xagoraris A, Romanski LM (1990): The lateral amygdaloid nucleus: sensory interface of the amygdala in fear conditioning. Journal of Neuroscience 10:1062-1069

LeMarquand D, Pihl RO, Benkelfat C (1994): Serotonin and alcohol intake, abuse, and dependence: findings of animal studies. Biological Psychiatry 36:395-421

Ma QP, Yin GF, Ai MK, Han JS (1991): Serotonergic projections from the nucleus raphe dorsalis to the amygdala in the rat. Neuroscience Letters 134:21-24

Magnusson O, Nilsson LB, Westerlund D (1980): Simultaneous determination of dopamine, DOPAC and homovanillic acid. Direct injection of supernatants from brain tissue homogenates in a liquid chromatography - electrochemical detection system. Journal of Chromatography 221:237-247

Melchior CL, Myers RD (1976): Genetic differences in ethanol drinking of the rat following injection of 6-OHDA, 5,6-DHT or 5,7-DHT into the cerebral ventricles. Pharmacology, Biochemistry \& Behavior 5:63-72

Morris JS, Friston KJ, Buchel C, Frith CD, Young AW, Calder AJ, Dolan RJ (1998): A neuromodulatory role for the human amygdala in processing emotional facial expressions. Brain 121:1-57

Myers RD, Melchior CL (1975): Alcohol drinking in the rat after destruction of serotonergic and catecholaminergic neurons in the brain. Research Communications in Chemical Pathology \& Pharmacology 10:363-378

Möller C, Sommer W, Thorsell A, Heilig M (1999): Anxiogenic-like action of galanin after intra-amygdala administration in the rat. Neuropsychopharmacology. 21:507512 
Möller C, Wiklund L, Sommer W, Thorsell A, Heilig M (1997): Decreased experimental anxiety and voluntary ethanol consumption in rats following central but not basolateral amygdala lesions. Brain Research 760:94101

Paxinos G, Watson C (1986): The rat brain in stereotaxic coordinates. $2^{\text {nd }}$ edition. Academic Press, San Diego

Pellow S, Chopin P, File SE, Briley M (1985): Validation of open: closed arm entries in an elevated plus-maze as a measure of anxiety in the rat. Journal of Neuroscience Methods 14:149-167

Pellow S, File SE (1986): Anxiolytic and anxiogenic drug effects on exploratory activity in an elevated plus-maze: a novel test of anxiety in the rat. Pharmacology Biochemistry \& Behavior 24:525-529

Perse TL, Greist JH, Jefferson JW, Rosenfeld R, Dar R (1987): Fluvoxamine treatment of obsessive-compulsive disorder. American Journal of Psychiatry 144:1543-1548

Pitkanen A, Savander V, LeDoux JE (1997): Organization of intra-amygdaloid circuitries in the rat: an emerging framework for understanding functions of the amygdala. Trends in Neurosciences 20:517-523

Pucilowski O, Plaznik A, Kostowski W (1985): Aggressive behavior inhibition by serotonin and quipazine injected into the amygdala in the rat. Behavioral \& Neural Biology 43:58-68

Richardson JS, Novakovski DM (1978): Brain monoamines and free choice ethanol consumption in rats. Drug \& Alcohol Dependence 3:253-264

Rocca P, Fonzo V, Scotta M, Zanalda E, Ravizza L (1997): Paroxetine efficacy in the treatment of generalized anxiety disorder. Acta Psychiatrica Scandinavica 95:444-450
Soderpalm B, Engel JA (1991): Involvement of the GABAA/ benzodiazepine chloride ionophore receptor complex in the 5,7-DHT Induced anticonflict effect. Life Sciences 49:139-153

Soubrié P (1986): Reconciling the role of central serotonin neurons in human and animal behavior. Behavioral Brain Science 9:319-364

Spanagel R, Montkowski A, Allingham K, Stohr T, Shoaib M, Holsboer F, Landgraf R (1995): Anxiety - a potential predictor of vulnerability to the initiation of ethanol self administration in rats. Psychopharmacology 122: 369-373

Thiebot MH, Soubrie P, Doare L, Simon P (1984): Evidence against the involvement of a noradrenergic mechanism in the release by diazepam of novelty-induced hypophagia in rats. European Journal of Pharmacology 100:201-205

Tsuiki K, Muck-Seler D, Diksic M (1995): Autoradiographic evaluation of the influence of hypothalamic 5,7-dihydroxytryptamine lesion on brain serotonin synthesis. Biochemical Pharmacology 49:633-642

Tye NC, Everitt BJ, Iversen SD (1977): 5-Hydroxytryptamine and punishment. Nature 268:741-743

Vogel JR, Beer B, Clody DE (1971): A simple and reliable conflict procedure for testing anti- anxiety agents. Psychopharmacologia 21:1-7

Whalen PJ, Rauch SL, Etcoff NL, McInerney SC, Lee MB, Jenike MA (1998): Masked presentations of emotional facial expressions modulate amygdala activity without explicit knowledge. Journal of Neuroscience 18:411-418 